\title{
New guidelines for the management of occupational asthma in primary care and occupational health
}

Why does asthma start or recur in an adult? The cause will be work in at least one out of every 10 adults of working age. It is hard to think of many other causes of adult asthma; some will be caused by beta blockers, a few by NSAID's, and some perhaps follow an acute respiratory illness or a large irritant exposure. When work is the cause, it affects your patient's livelihood as well as their health. This month sees the publication of full evidenced based guidelines for the management of patients with occupational asthma [1]. The guidelines supplement the recent SIGN/BTS asthma guidelines [2], which did not extend the evidence review to occupational asthma. The guidelines were sponsored by BOHRF (British Occupational Health Research Foundation), a charity sponsoring research of practical value in occupational health (including recent guidelines which improve the management of workers with low back pain) [3].

Occupational asthma is the commonest occupational lung disease in westernised countries. All primary care health professionals are likely to have affected patients, who will often see their General Practitioner (GP) or Practice Nurse as their first medical contact. All family practices should be able to screen for occupational asthma, and have a plan for further management.

Occupational asthma tends to occur in clusters. Spray painters, bakers, nurses, chemical workers, animal handlers, food processors, welders and timber workers are amongst those at highest risk. The most common causes are isocyanates, flour, grain, colophony, fluxes, latex, animals, aldehydes, welding fume and wood dusts, although cases can occur almost anywhere.

All is not well in the management of patients with occupational asthma. The diagnosis is frequently delayed for many years, increasing the likelihood of long-term disability. Expert opinion is often hard to find. Approximately one third of patients are unemployed up to 6 years after diagnosis [1]. There is good evidence that early detection and removal from exposure improves prognosis, but that leaving work often leads to substantial loss of income. The best solution is to modify the workplace. If a doctor or nurse developed latex asthma would you expect them to be told to leave their job? Do we advise spray painters, master bakers or welders any differently? Many nurses and a few doctors have developed severe latex allergy, to the extent that they cannot enter healthcare premises without exacerbating their asthma. Once identified, affected individuals can be relocated to areas without latex gloves. Cornstarch used to powder gloves acts as a carrier for the latex allergen. Removing powder from latex gloves reduces the airborne latex levels preventing further workers from developing latex induced asthma and permitting some asthmatic patients to return to the workplace. There remains further scope for substituting latex for less allergenic materials in medical gloves.

Screening for occupational asthma is easy. All adult asthmatics should be asked whether their symptoms improve on days away from work or on holiday. Few cases are missed by these questions, but they lack specificity i.e. they pick out many who do not have occupational asthma. Further confirmation is needed before important life decisions are made. The BTS/SIGN guidelines [2] recommend specialist referral for these patients; some countries, for example the United Kingdom do not have many specialists in occupational lung diseases. Occupational-style serial measurements of peak expiratory flow are possible in primary care, but require enthusiasm and attention to detail. The aim is to see if occupational exposure provokes the 
asthma. Once occupational asthma has developed, the peak expiratory flow will be influenced by waking time (often earlier on workdays), treatment and other provoking factors such as exercise and cold air. The guidelines recommend measurements at least 4-times daily (or even better two-hourly), over 4 weeks with daily recording of waking and sleeping times, and times starting and stopping work. Diagnostic records are best made before treatment is increased and workplace modifications made. Once recorded they need to be analysed by an expert. Advice and record forms are available on the website http://www.occupationalasthma.com [4]. This site also has links to the full guidelines [1]. Other means of confirmation include immunological and challenge tests, which require referral to a specialist.

The best outcomes leave a worker employed and without exposure to the causative agent within a year of the first work-related symptom. GP's should not recommend patients to leave their employment as a means of avoiding exposure, except as a last resort. This leaves an unemployed patient who is likely to have problems with re-employment, and will minimize the chances of remedial action in the workplace. Having obtained patient consent the employer should be told of the agent that your patient needs to avoid. The employer should also take steps to prevent further cases. This clearly needs an accurate diagnosis which often requires specialist referral; specialists should also be able to advise on compensation issues.

\section{References}

[1] Newman Taylor AJ, Nicholson PJ (Editors). Guidelines for the prevention, identification and management of occupational asthma: Evidence review and recommendations. British Occupational Health Research Foundation, London 2004.

[2] British Thoracic Society; Scottish Intercollegiate Guidelines Network. British guideline on the management of asthma. Thorax 2003: 58 Suppl 1:i1-94. (http://www.brit-thoracic. org.uk/sign/index.htm) last accessed May 2004.

[3] Carter JT, Birrell LN (Editors). Occupational health guidelines for the management of low back pain at work - principal recommendations. Faculty of Occupational Medicine. London. 2000 http://www.facoccmed.ac.uk/Content/ BackPain.htm.

[4] http://www.occupationalasthma.com (Last accessed May 2004).

P. Sherwood Burge Occupational Lung Disease Unit Birmingham Heartlands Hospital Green East, Birmingham B9 5SS, UK A IIV C Tel.: +441214240734 E-mail address: burgeps@aol.com ibltec (P. Sherwood Burge)

14 June 2004

Available online at www.sciencedirect.com science $(\mathcal{b}$ direct. 